\title{
MATERNAL RISK FACTORS AND FETAL OUTCOME IN PATIENTS OF ABRUPTION PLACENTAE.
}

1. MBBS, FCPS

Assistant Professor (Obs \& Gynae)

Azra Naheed Medical College, Chaudhry Muhammad Akram

Teaching Research Hospital, Lahore.

2. MBBS, FCPS

Senior Registrar (Obs \& Gynae) University of Lahore Teaching Hospital, Lahore.

3. MBBS, FCPS

Senior Registrar (Obs \& Gynae) University of Lahore Teaching Hospital, Lahore.

4. MBBS, FCPS

Assistant Professor (Obs \& Gynae) Azra Naheed Medical College Chaudhry Muhammad Akram Teaching Research Hospital, Lahore.

5. MBBS, FCPS

Consultant Gynecologist Ali General Hospital, Multan.

Correspondence Address: Dr. Humaira Tabassum Azra Naheed Medical College, Chaudhry Muhammad Akram Teaching Research Hospital, Lahore. humairakashif100@gmail.com

Article received on:

22/05/2019

Accepted for publication:

00/00/2019

\section{INTRODUCTION}

Abruption placenta is defined as detachment of placenta before delivery. Approximately $0.7 \%$ to $1.0 \%$ singleton pregnancies have abruption placenta. ${ }^{1-3}$ The incidence increases in twin up to $1 \%$ to $2 \% .^{4,5}$ Even though abruption placenta is not very common; it is still a major cause of fetal and neonatal mortality. This high mortality in abruption placenta can be linked to its association with preterm birth. ${ }^{6}$ More than $50 \%$ of fetal death in abruption placenta was because of premature delivery. ${ }^{6}$ There are many maternal complications as well because of abruption; however the major complications are life threatening blood loss, DIC and sepsis, kidney failure and even maternal death in few cases. ${ }^{7}$ While the incidence of placenta abruption is $1 \%$, it is still not well understood. ${ }^{8}$ Mortality.

\section{Humaira Tabassum ${ }^{1}$, Memoona Faiyaz ${ }^{2}$, Aasma Hanif ${ }^{3}$, Uzma Fahim ${ }^{4}$, Areeba Aftab ${ }^{5}$}

ABSTRACT: Abruption placentae are a major cause of maternal and perinatal morbidity factors, perinatal mortality and morbidity in relation to the severity of placental abruption. Study Hunded Lahore for one year. Period: From Jan 2016 to Dec 2016. Material \& Methods: the time of delivery maternal and fetal complications were noted. Results: Mean age of females was $29.24+3.58$ years. The mean gestational age at delivery was $32.95+3.12$ weeks. About (a) only $42 \%$ were born alive at time of delivery. Fetal morbidity is a resuscitation, admission to nursery was done in $95.23 \%$, neonatal jaundice was seen in $80.95 \%$, am 21 alive born fetuses was $<8$ in $85.71 \%$. Conclusion. Resultantly maternal morbidity surveillance. There should be timely referral to tertiary care center where antenatal care plays an important role in decreasing the incidence of abruption placenta.

\section{Key words: $\quad$ Abruption Placentae, Apgar Score, Cesarean Section, Perinatal Morbidity \&} 2020; 27(3):613-617. DOI: 10.29309/TPMJ/2020.27.3.3744

Major risk factors responsible for placental abruption are increase maternal age, smoking and abuse of cocaine, multiparity, woman of poor socio-economic status, multiple births, black woman, male child, hypertensive disease in mother and intrauterine infections..$^{4,9-15}$ However, the strongest associated factor with placental abruption is history of abruption in previous pregnancy. ${ }^{16,17,18}$ Despite being associated with grave maternal and fetal complications, clinical data on abruption, particularly local data is grave. It is important to recognize risk factors and complications associated with abruption, so that appropriate management plan can be made for pregnant women who are at risk of abruption. In this study, we assess the perinatal mortality and morbidity and risk factors in patients with 
abruption placenta.

\section{MATERIAL AND METHODS}

This was a cross-sectional study conducted in department of Obstetrics and Gynecology, Jinnah Hospital Lahore from Jan 2016 to Dec 2016. During this period, total of 100 patients admitted at the time of their delivery with already established diagnosis of placental abruption after 24 weeks of gestation were included. After taking informed consent data was collected for selected cases. Data included age, parity, gestation age, predisposing factors and symptoms of abruption placentae. Mode of delivery, Neonatal Apgar Score at birth and five minute and fetal morbidity was also noted. The morbidity in the form of admission in neonatology unit for more than 48 hours and any complication developed was considered morbid. The data was analyzed using SPSS version 21. Calculating mean and standard deviation for numerical data like age, gestational age and APGAR score. Frequency and percentage were calculated for qualitative variables like parity, maternal and fetal outcome, predisposing factors like hypertension, anaemia, polyhydramnios and multiple pregnancy, symptoms of abruption placentae.

\section{RESULTS}

The mean age of patients was $29.24+3.58$ years. The mean gestational age at delivery was $32.95+3.12$ weeks. The parity distribution shows $10(10 \%)$ having parity 0 (Primigravida), 48(48\%) having parity $1-2,48(48 \%)$ with $3-4$ parity and $\geq 5$ parity in 26(26\%). Table-I.

In this study, 64 (64\%) underwent normal vaginal delivery while 36 (36\%) underwent cesarean section. Pre-disposing factors of abruption placentae in this research work are showing increased risk of anemia i.e. 46(46\%), hypertension was found in $28(28 \%)$, multiple pregnancy with $18(18 \%)$ and polyhydromnias were found in $8(8 \%)$ (Table-I). There were 42 fetuses delivered alive while 58 (58\%) died during delivery or soon after delivery. After 5 minutes of birth, Apgar score of 42 alive fetuses was noted $<8$ in $36(85.7 \%)$. Fetal morbidity is analyzed, where among 42 alive born fetuses, 40 (95.2\%) were in need of resuscitation, admission to nursery was done in 40 (95.2\%), neonatal jaundice was seen in $34(81 \%)$, anemia in $30(71.4 \%)$ and respiratory problems were found in 36 (85.7\%). Table-II.

\begin{tabular}{|l|c|c|}
\hline \multirow{3}{*}{$\begin{array}{l}\text { Mode of } \\
\text { Delivery }\end{array}$} & Vaginal Delivery & $\mathbf{F ~ ( \% )}$ \\
\cline { 2 - 3 } & Cesarean Delivery & $36(64 \%)$ \\
\hline \multirow{3}{*}{ Factors } & Hypertension & $28(28 \%)$ \\
\cline { 2 - 3 } & Anemia & $46(46 \%)$ \\
\cline { 2 - 3 } & Polyhydramnios & $8(8 \%)$ \\
\cline { 2 - 3 } & Multiple pregnancy & $18(18 \%)$ \\
\hline
\end{tabular}

Table-I. Maternal Risk Factor placental abruption.

\begin{tabular}{|l|c|c|}
\hline \multirow{3}{*}{ Fetal Mortality } & Yes & $58(58 \%)$ \\
\cline { 2 - 3 } Apgar score & No & $42(42 \%)$ \\
\hline \multirow{4}{*}{ Fetal Morbidity } & $8-10$ & $36(85.7 \%)$ \\
\hline \multirow{3}{*}{} & Resuscitation required & $40(14.3 \%)$ \\
\cline { 2 - 3 } & Admission to nursery & $40(95.2 \%)$ \\
\cline { 2 - 3 } & Neonatal jaundice & $34(81.0 \%)$ \\
\cline { 2 - 3 } & Anemia & $30(71.4 \%)$ \\
\cline { 2 - 3 } & Respiratory problem & $36(85.7 \%)$ \\
\hline
\end{tabular}

Table-II. Fetal outcome of placental abruption.

\section{DISCUSSION}

Abruption placentae are one of the grave complications of pregnancy. It has very high maternal and perinatal mortality as well as morbidity. These can be avoided by treating shock and conducting early delivery preferably by vaginal route. While this study adds to limited local data available on abruption, because of its crosssectional nature it was not able to establish causal relationship between risk factors and abruption. Large scale multi-centric prospective studies are needed to further establish associations between risk factors and abruption.

Parity of patients is a risk factor of abruption placentae in many studies. ${ }^{19-26}$ Multiparity, particularly grand multiparity has been specified as a factor predisposing to increased frequency of abruption placentae. The number of multiparous females in this study was 90 (90\%), while primigravida were only 10 (10\%). Of the multiparous females, $32(64 \%)$ were in the multigravida group ( 1 - 4 children) and 26 (26\%) 
were grand multigravida (more than 4 children). Hence, multiparty can be consider as risk factor for abruption placentae.

Forty six (46\%) patients had anaemia, with haemoglobin levels of severe to moderate anaemia. This high prevalence of anemia can be because of bleeding that occurs in abruption. Another reason for high prevalence of anemia can be nutritional deficit, which is very common in pregnant woman in this country. Another local study supports our finding of high number of patients with anemia; as they reported $34.4 \%$ of patients with abruption placentae have anemia. ${ }^{27}$

The patients in this study had a frequency of hypertension in $28 \%$ cases. This number may be even higher as actual blood pressure at the time of delivery may be masked because of bleeding due to abruption placentae. Various authors have studies role of hypertension. Abdella $^{28}$ noted that incidence of abruption was highest in woman who had eclampsia (23.6\%), followed by chronic hypertension (10.0\%) and then pre-eclampsia (2.3\%). Abdella [28] helped established that hypertension is associated with increased incidence of abruption and is associated more with eclampsia than any other hypertensive disorder. Similar findings were seen by Sharief and Manther;29 In their study they compared hypertensive and normotensives pregnant woman and found that there is increase incidence of abruption in hypertensive group.

In this study, fetal mortality was very high. Fifty eight (58\%) patients had intra-uterine fetal mortality. These high fetal mortality can be attributed to either abruption placentae itself or one its complication. Similar high fetal mortality was found in studies from neighboring countries such as India and Iraq. ${ }^{29}$

To summarize, abruption placentae is a serious obstetric problem with very high neonatal mortality and morbidity and grave influence on maternal health. It is important that efforts should be made to recognize woman at risk of abruption placentae early and high risk management strategies should be adopted to reduce the risk.

\section{CONCLUSION}

In this study, multiparity and hypertensive disorders were strong predictors of abruption placentae. Fetal mortality was very high. Hence is very important for early detection, regular visits and strict surveillance. Our results give relevant information to physicians regarding risk factors for abruption placentae which may help identify woman at risk of abruption placentae. Considering high fetal mortality, it is important to improve attendance to antenatal care and timely management of the risk factors associated with abruption placentae.

Copyright $@$

\section{REFERENCES}

1. Ananth CV, Savitz DA, Williams MA. Pracental abruption and its association with hypertension and prolonged rupture of membranes: A methodologic review and meta-analysis. Obstetrics \& Gynecology 1996; 88(2):309-18.

2. Rasmussen S, Irgens LM, Bergsjø P, Dalaker K. The occurrence of placental abruption in Norway 19671991. Acta obstetricia et gynecologica Scandinavica 1996; 75(3):222-8.

3. Ananth CV, Berkowitz GS, Savitz DA, Lapinski RH. Placental abruption and adverse perinatal outcomes. Jama 1999; 282(17):1646-51.

4. Ananth CV, Smulian JC, Demissie K, Vintzileos AM, Knuppel RA. Placental abruption among singleton and twin births in the United States: Risk factor profiles. American journal of epidemiology 2001; 153(8):771-8.

5. Pariente G, Wiznitzer A, Sergienko R, Mazor M, Holcberg $\mathrm{G}$, Sheiner E. Placental abruption: Critical analysis of risk factors and perinatal outcomes. The Journal of Maternal-Fetal \& Neonatal Medicine 2011; 24(5):698702.

6. Ananth CV, Wilcox AJ. Placental abruption and perinatal mortality in the United States. American journal of epidemiology 2001; 153(4):332-7.

7. BRAME RG, HARBERT GM, Mc Gaughey H, Thornton W. Maternal risk in abruption. Obstetrics \& Gynecology 1968; $31(2): 224-7$.

8. Ananth CV, Smulian JC, Vintzileos AM. Incidence of placental abruption in relation to cigarette smoking and hypertensive disorders during pregnancy: A meta-analysis of observational studies. Obstetrics \& Gynecology 1999; 93(4):622-8. 
9. Abdella TN, Sibai BM, Hays JJ, Anderson GD. Relationship of hypertensive disease to abruptio placentae. Obstetrics and gynecology 1984; 63(3):36570.

10. Voigt LF, Hollenbach KA, Krohn MA, Daling JR, Hickok $D E$. The relationship of abruptio placentae with maternal smoking and small for gestational age infants. Obstetrics and gynecology 1990; 75(5):771-4.

11. Ananth CV, Wilcox AJ, Savitz DA, Bowes Jr WA, Luther ER. Effect of maternal age and parity on the risk of uteroplacental bleeding disorders in pregnancy. Obstetrics \& Gynecology 1996; 88(4):511-6.

12. Darby MJ, Caritis SN, Shen-Schwarz S. Placental abruption in the preterm gestation: An association with chorioamnionitis. Obstetrics and gynecology 1989; 74(1):88-92.

13. Vintzileos AM, Campbell WA, Nochimson DJ, Weinbaum PJ. Preterm premature rupture of the membranes: A risk factor for the development of abruptio placentae. American journal of obstetrics and gynecology 1987; 156(5):1235-8.

14. Misra DP, Ananth CV. Risk factor profiles of placental abruption in first and second pregnancies: Heterogeneous etiologies. Journal of clinical epidemiology 1999; 52(5):453-61.

15. Ananth CV, Savitz DA, Bowes WA, Luther ER. Influence of hypertensive disorders and cigarette smoking on placental abruption and uterine bleeding during pregnancy. BJOG: An International Journal of Obstetrics \& Gynaecology 1997; 104(5):572-8.

16. Kåregård M, Gennser $G$. Incidence and recurrence rate of abruptio placentae in Sweden. Obstetrics and gynecology 1986; 67(4):523-8.

17. Lydon-Rochelle M, Holt VL, Easterling TR, Martin DP. First-birth cesarean and placental abruption or previa at second birth. Obstetrics \& Gynecology 2001; 97(5):765-9.

18. Saftlas AF, Olson DR, Atrash HK, Rochat R, Rowley $D$. National trends in the incidence of abruptio placentae, 1979-1987. Obstetrics and gynecology 1991; 78(6):1081-6.
19. Toivonen S, Heinonen S, Anttila M, Kosma V-M, Saarikoski S. Reproductive risk factors, Doppler findings, and outcome of affected births in placental abruption: A population-based analysis. American journal of perinatology 2002; 19(08):451-60.

20. Sheiner E, Shoham-Vardi I, Hallak M, Hadar A, GortzakUzan L, Katz M, et al. Placental abruption in term pregnancies: clinical significance and obstetric risk factors. The Journal of Maternal-Fetal \& Neonatal Medicine 2003; 13(1):45-9.

21. Abu-Heija A, Al-Chalabi H, El-lloubani N. Abruptio placentae: risk factors and perinatal outcome. Journal of Obstetrics and Gynaecology Research 1998; 24(2):141-4.

22. Williams MA, Lieberman E, Mittendorf R, Monson RR, Schoenbaum SC. Risk factors for abruptio placentae. American journal of epidemiology 1991; 134(9):965-72.

23. Asaf $\mathrm{KH}$. Grand multiparity: Still an obstetric risk factor. Pak J Obstet Gynecol 1997; 10(1\&2):24-8.

24. Rai L, Duvvi H, Rao U, Nalini V. Severe abruptio placentae-still unpreventable. International Journal of Gynecology \& Obstetrics 1989; 29(2):117-20.

25. James DK, Steer PJ, Weiner CP, Gonik B, Robson SC. High-risk pregnancy: Management options: Cambridge University Press; 2017.

26. Kyrklund-Blomberg NB, Gennser G, Cnattingius S. Placental abruption and perinatal death. Paediatric and perinatal epidemiology 2001; 15(3):290-7.

27. Liaquat N, Shoib T, Shuja S. A study of abruptio placentae. J surg Pakistan 2006; 11:27-30.

28. Nakatsuka M, Asagiri K, Kimura Y, Kamada Y, Tada K, Kudo T. Generation of peroxynitrite and apoptosis in placenta of patients with chorioamnionitis: possible implications in placental abruption. Human Reproduction 1999; 14(4):1101-6.

29. Sharief M, Manther A. Abruptio placentae: Perinatal out come in normotensive and hypertensive patients in Basra, Iraq. 1998. 


\begin{tabular}{|c|c|c|c|}
\hline \multicolumn{4}{|c|}{ AUTHORSHIP AND CONTRIBUTION DECLARATION } \\
\hline Sr. \# & Author(s) Full Name & Contribution to the paper & Author(s) Signature \\
\hline 1 & Humaira Tabassum & 1st Author & aika \\
\hline 2 & Memoona Faiyaz & 2nd Author & \\
\hline 3 & Aasma Hanif & 3rd AUthor & 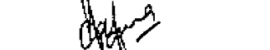 \\
\hline 4 & Uzma Fahim & 4th Aathor & DXrmq \\
\hline 5 & Areeba Aftab & 5th Author & Aaba Aftolu \\
\hline
\end{tabular}

